\title{
Fluorination of sized glass fibres for decreased wetting by atmospheric pressure plasma treatment in He/CF4
}

\author{
Hottentot Cederløf, Daan Jonas; Kusano, Yukihiro; Fæster, Søren
}

Published in:

Journal of Adhesion

Link to article, DOI:

$10.1080 / 00218464.2019 .1686364$

Publication date:

2019

Document Version

Early version, also known as pre-print

Link back to DTU Orbit

Citation (APA):

Hottentot Cederløf, D. J., Kusano, Y., \& Fæster, S. (2019). Fluorination of sized glass fibres for decreased wetting by atmospheric pressure plasma treatment in He/CF4. Journal of Adhesion, 96(1-4), 2-12.

https://doi.org/10.1080/00218464.2019.1686364

\section{General rights}

Copyright and moral rights for the publications made accessible in the public portal are retained by the authors and/or other copyright owners and it is a condition of accessing publications that users recognise and abide by the legal requirements associated with these rights.

- Users may download and print one copy of any publication from the public portal for the purpose of private study or research.

- You may not further distribute the material or use it for any profit-making activity or commercial gain

- You may freely distribute the URL identifying the publication in the public portal

If you believe that this document breaches copyright please contact us providing details, and we will remove access to the work immediately and investigate your claim. 


\title{
Fluorination of sized glass fibres for decreased wetting by atmospheric pressure plasma treatment in $\mathrm{He} / \mathrm{CF}_{4}$
}

\author{
Daan J. Hottentot Cederløf ${ }^{a, *}$, Yukihiro Kusano ${ }^{a}$, Søren Fæster ${ }^{a}$ \\ ${ }^{a}$ Wind Energy Department, Technical University of Denmark, 4000 Roskilde, Denmark
}

\begin{abstract}
Sized glass fibre bundles were treated using atmospheric pressure plasma in a helium/ tetrafluoromethane gas mixture. X-ray photoelectron spectroscopy showed that fluorine was introduced onto the sizing surface. A new analysis method (dynamic micro-wetting) to determine the wetting rate of the plasma treated fibre bundles is presented. The dynamic micro-wetting test using glycerol as a test liquid showed a reduced wetting rate after plasma treatment. It is demonstrated that dynamic micro-wetting is a useful tool for characterization of fibre bundle wetting.
\end{abstract}

Keywords: surface treatment, plasma, fibres, wetting

\section{Introduction}

Glass fibre composites are widely used in applications where high stiffness, low weight and low cost are required, for example in ship hulls and wind turbine blades. A common damage mechanism in composites is delamination, where adjacent plies are separated, due to out-of-plane loading, impact

\footnotetext{
${ }^{*}$ Corresponding author.

Email address: dace@dtu.dk (Daan J. Hottentot Cederløf)
} 
events, bolted joints or other stress concentrations. As delamination fronts (delamination cracks) grow, either statically or cyclically, structural failure may occur due to a loss of stiffness. ${ }^{[1,2]}$ Various methods exist for reducing delaminations such as z-pinning ${ }^{[3]}$ and inclusion of toughening particles. ${ }^{[4]}$ Alternatively, a conservative design approach may be adopted, however this leads to an unnecessarily heavy structure.

Rask and Sørensen, ${ }^{[5]}$ showed experimentally that when multiple delamination cracks (concept illustrated in fig. 1) occurred in double cantilever beam (DCB) specimens, the resistance to crack growth scaled proportionally to the additional number of delamination cracks. However, the occurrence of multiple delamination cracks was not controlled. Further numerical studies of DCB specimens by Goutianos and Sørensen ${ }^{[6]}$-with a second cohesive interface parallel to the primary crack interface- showed that in order to control the formation of a second crack, the interlaminar tensile strength (denoted $\sigma_{22}^{2}$ in fig. 1) of the second interface must be lower than the $\sigma_{22}^{1}$ of the primary crack interface. In other words, a weak plane must be introduced near the primary crack plane to form a second crack.

Introducing a weak plane may be achieved by inclusion of a polytetrafluoroethelene (PTFE) slip foil, a common technique for initiation of cracks in delamination experiments. To reduce the severity of a complete disbond, the PTFE foil may be perforated, so as to maintain a certain amount of interlaminar strength; as demonstrated by Kuhtz et al. ${ }^{[7]}$ However, any physical barrier (with or without perforations) will hinder the formation of fibre bridg- 


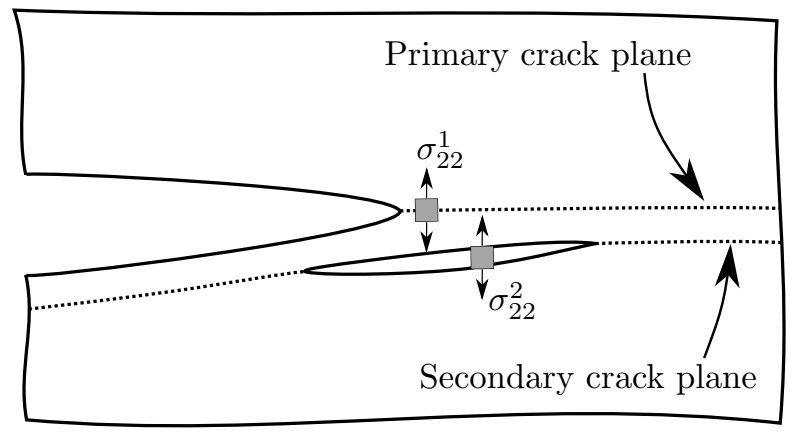

Figure 1: Illustration of the formation of multiple delamination cracks in a composite DCB specimen. The superscripts 1 and 2 refer to the primary and secondary crack planes, respectively.

ing. It is shown that fibre bridging is a toughening mechanism which is useful for reducing crack growth. ${ }^{[8]}$ Fluorination of fibres, by plasma treatment prior to infusion, may be used to locally introduce a weak interface without the use of a physical barrier.

Atmospheric plasma treatment is an attractive surface modification because of its low environmental impact, selectivity in treatment and compatibility with a wide range of materials. Furthermore, it can be limited to treating material surfaces without influencing bulk properties; the treatment depth is in the order of $10 \mathrm{~nm} .{ }^{[9]}$ Polymerization, deposition, ablation and substitution can occur depending on the gas introduced in the plasma. ${ }^{[10]}$ For example using a helium/ammonia $\left(\mathrm{He} / \mathrm{NH}_{3}\right)$ mixture may introduce nitrogen onto a polymer surface. ${ }^{[11]}$ Tetrafluoromethane $\left(\mathrm{CF}_{4}\right)$ is commonly used in plasma treatment of surfaces and may be used to fluorinate a polymer surface creating a de-wetting surface similar to PTFE. ${ }^{[12]}$ To the authors 
best knowledge, atmospheric pressure plasma treatment to locally fluorinate sized glass fibres, has not been reported before.

In all commercial glass fibre production a thin organic surface coating called sizing is applied to glass fibres to promote compatibility with the matrix. Sizing provides critical properties to the fibres and finished composite part, including: good wetting, resistance to environmental factors and a fibrematrix interphase capable of stress transfer. ${ }^{[13]}$ It is also demonstrated by $\mathrm{Xu}$ et al. ${ }^{[14]}$ that sizing acts as a filler, reducing the fibre surface roughness and reducing the occurrence of microvoids in the fibre/matrix interface. Sizing thickness is typically in the range of $0.1 \mu \mathrm{m}-10 \mu \mathrm{m}$, which is $1-3$ orders of magnitude larger than the plasma treatment depth of $10 \mathrm{~nm}$. After plasma treatment, the bulk glass fibre material and the protective role of the sizing therefore remain unchanged.

The current paper investigates the influence of dielectric barrier discharge (DBD) plasma in a $\mathrm{He} / \mathrm{CF}_{4}$ mixture on the surface of commercial sized glass fibre with the aim of introducing fluorine on the sizing surface. A technique of dynamic micro-wetting is presented for measuring the wetting of bundles of fibres. This technique is used to determine the change in wetting behaviour of glycerol on glass fibre bundles. X-ray photoelectron spectroscopy (XPS) and field emission scanning electron microscopy (FE-SEM) are used to characterize the elemental and morphological change of the sizing surface after plasma treatment. 


\section{Method}

Specimens containing several bundles of sized glass fibres were cut from a non-crimp UD-0 fabric without backing reinforcement. The specimens were treated with an atmospheric pressure DBD plasma generated in a mixture of helium (He) and tetrafluoromethane $\left(\mathrm{CF}_{4}\right)$ (see fig. 2). The DBD was supplied with 3.0 SLM (standard liter per minute) of He, mixed with $0.23 \mathrm{SLM}$ of $\mathrm{CF}_{4}$. The DBD was generated between 2 water cooled electrodes; the bottom electrode (a $50 \mathrm{~mm} \times 50 \mathrm{~mm}$ metal plate) covered by a $100 \mathrm{~mm} \times 100 \mathrm{~mm} \times 3 \mathrm{~mm}$ Alumina dielectric barrier; the top electrode is a $50 \mathrm{~mm} \times 50 \mathrm{~mm}$ metal mesh electrode. ${ }^{[15]}$ Power was supplied by an alternating-current (AC) generator at approx. $40 \mathrm{kHz}$ (Generator 6030. SOFTAL Electronic GmbH, Hamburg, Germany). A high-voltage probe (PPE $20 \mathrm{kV}$, LeCroy, Chestnut Ridge, NY, USA) and a $50 \Omega$ shunt resistor were used to measure voltage and current, to determine average power input. Treatment time was $60 \mathrm{~s}$, plasma power was $50 \mathrm{~W}$ or $100 \mathrm{~W}$.

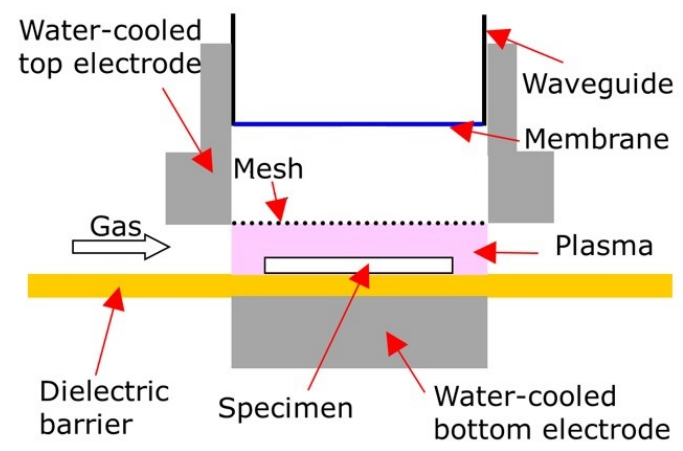

Figure 2: DBD treatment test setup 


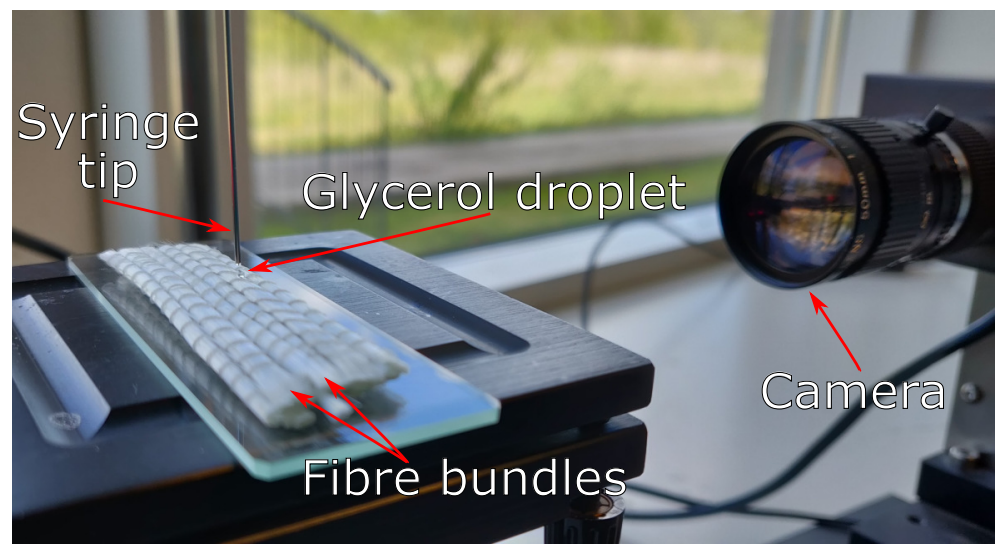

Figure 3: Contact angle measurement setup. (Full colour image available online.)

Dynamic micro-wetting tests were performed by applying a droplet (ca. $1 \mu \mathrm{L}$ ) of glycerol onto a single bundle of glass fibres using a threaded plunger syringe (setup shown in fig. 3). Glycerol was used as a test liquid because, like typical uncured resin, it has both polar and non-polar structures. Furthermore, its viscosity is representative of resin used for vacuum infusion of glass fibre composites. ${ }^{[16]}$ As it wets more slowly than water it is easier to record the wetting process. A similar method, albeit with a different data processing method, is described by Shin et al. ${ }^{[17]}$ Stitching fibres were not removed from the bundles in order to maintain the bundle structure. A video of the droplet was video recorded (CAM100. Crelab Instruments AB, Billdal, Sweden) as it reduced in height and spread into the bundle. Contact angles $(\theta)$ were measured at fixed time intervals and fitted with an exponential function (eq. (1)) using the curve fitting toolbox (cftool) in Matlab. In eq. (1) the constant, A, is related to the initial contact angle (i.e. eq. (1) evaluated at $\mathrm{t}=0)$. The $\alpha$ term is a measure of the wetting rate of the droplet. Measurements were performed on at least 2 points per bundle with a minimum 
of 3 bundles measured per treatment type.

$$
\cos (\theta)=1-A \cdot e^{-\alpha \cdot t}
$$

The surface structure of the glass fibres was observed by FE-SEM (Zeiss Ultra 55, Oberkochen, Germany). Specimens were sputter coated with gold (ca. $7 \mathrm{~nm}$ ) prior to microscopy.

Elemental composition of the fibre surface was analysed by XPS. Fibre bundles were analysed using a micro focused monochromatic $\mathrm{Al} \mathrm{K} \alpha \mathrm{X}$-ray source (K-alpha, ThermoFischer Scientific, Paisley, UK). An X-ray energy of $1486.6 \mathrm{eV}$ was used, resulting in a lateral resolution of $30 \mu \mathrm{m}$. A high resolution analysis of the carbon $1 \mathrm{~s}(\mathrm{C} 1 \mathrm{~s})$ was performed with spectra acquired over 30 scans. De-convolution was performed by curve fitting with purely Gaussian components with linear background subtraction. A fullwidth at half-maximum of $1.5 \mathrm{eV}$ was used for $\mathrm{C} 1 \mathrm{~s}$ peaks. The peaks at roughly $285 \mathrm{eV}, 286.5 \mathrm{eV}$ and $289.5 \mathrm{eV}$ can be assigned to $\mathrm{C}-\mathrm{H} / \mathrm{C}-\mathrm{C}, \mathrm{C}-\mathrm{O}-$

$\mathrm{C} / \mathrm{C}-\mathrm{OH}$ and $\mathrm{C}-\mathrm{F}$, respectively. ${ }^{[18]}$ Fibre samples were taken from both the bundle exterior and interior to determine treatment uniformity through the bundle cross-section. At least 3 points were analyzed per specimen.

\section{Results}

The results of the dynamic micro-wetting test are shown in table 1, where constant (A) and constant $(\alpha)$ are introduced in eq. (1) in the methodology. 
A larger wetting rate, $\alpha$, indicates faster wetting. A significant decrease in wetting rate was observed during the dynamic micro-wetting tests of the plasma treated specimens. Untreated specimens showed full wetting within $60 \mathrm{~s}$ whereas specimens treated at $100 \mathrm{~W}$ took $>600 \mathrm{~s}$.

Table 1: Dynamic micro-wetting test results: constant $\mathrm{A}$ and wetting rate $\alpha$ of contact angles.

\begin{tabular}{llllll}
\hline \multirow{2}{*}{ Power [W] } & \multicolumn{2}{l}{ Constant, A } & \multicolumn{2}{l}{ Wetting rate, $(\alpha)$} & No. measurements \\
& Avg & \pm & Avg & \pm & \\
\hline untreated & 0.918 & 0.225 & 0.091 & 0.071 & 36 \\
50 & 1.000 & 0.223 & 0.012 & 0.015 & 56 \\
100 & 0.931 & 0.197 & 0.004 & 0.005 & 12 \\
\hline
\end{tabular}

FE-SEM images of untreated fibre surface (figs. 4a and 4c) are compared to $100 \mathrm{~W}$ treated fibres (figs. $4 \mathrm{~b}$ and 4d). Circular 'island' formations with a diameter in the order of $200 \mathrm{~nm}$ are recognized in both figs. $4 \mathrm{~b}$ and $4 \mathrm{c}$, these types of features were observed on all glass fibres with sizing, before and after plasma treatment (also at $50 \mathrm{~W}$ ). The FE-SEM images generally show a smooth surface, however cracks with length of $100 \mathrm{~nm}-200 \mathrm{~nm}$ were observed on both treated and untreated specimens at higher magnification (figs. 4c and 4d).

XPS spectra of the plasma treated and untreated fibres are shown in fig. 5. The elemental surface compositions are summarised in table 2. A peak at 
$688 \mathrm{eV}$ is observed for fibres treated with plasma indicating that the surface contained fluorine. Fluorine is detected after plasma treatment, on fibres from the interior and exterior of the bundle. The more powerful treatment of $100 \mathrm{~W}$ shows a higher fluorine content, shown by the increased $\mathrm{F}$ :C ratio in table 2 and larger fluorine peak in fig. 5a compared to fig. 5b. An increase in the $\mathrm{O}: \mathrm{C}$ ratio is observed on interior and exterior fibres for both $50 \mathrm{~W}$ and

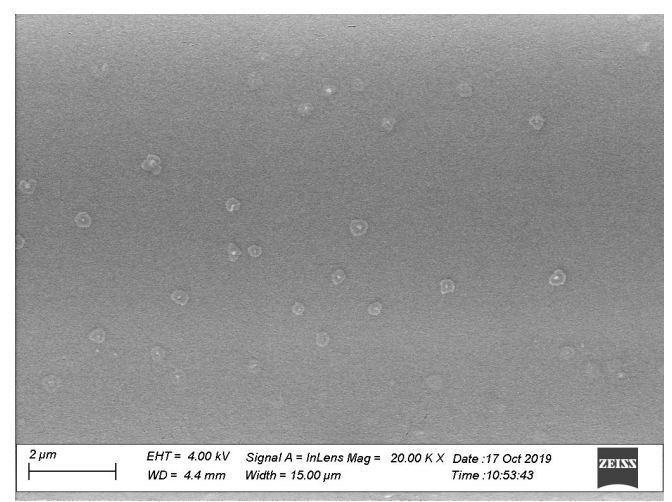

(a) Untreated fibre.

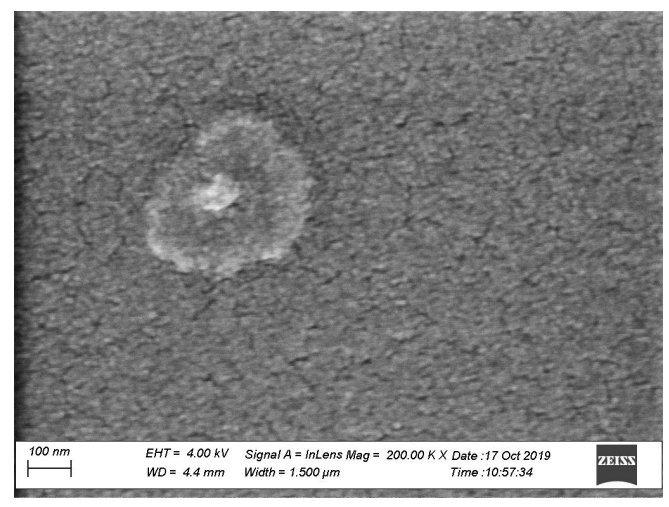

(c) Untreated fibre.

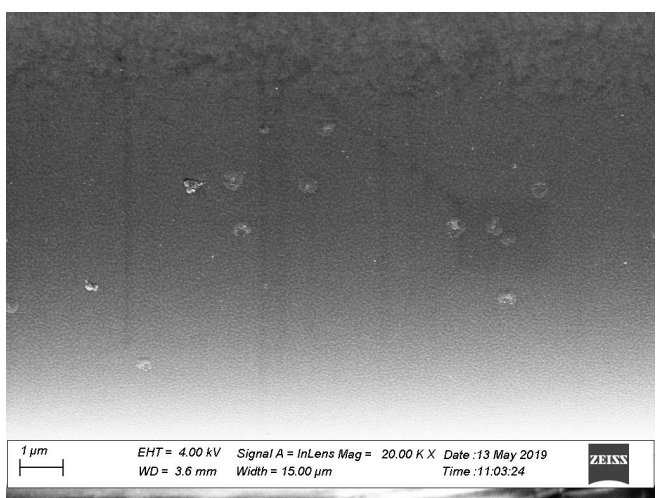

(b) Treatment: DBD 100W.

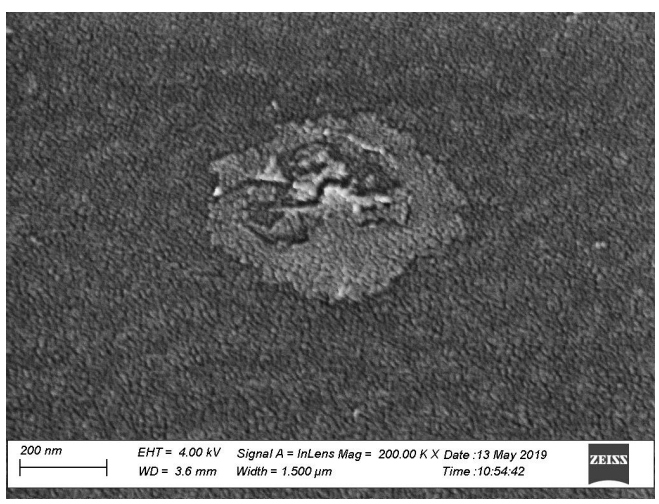

(d) Treatment: DBD 100W.

Figure 4: FE-SEM images of fibres before and after plasma treatment. (Fibre diameter $=17 \mu \mathrm{m})$ 
$100 \mathrm{~W}$ treatments. Figure 6 shows typical C1s spectra of the treated and untreated fibres. The peaks labelled Scan A, Scan B and Scan C correspond to $\mathrm{C}-\mathrm{H} / \mathrm{C}-\mathrm{C}, \mathrm{C}-\mathrm{O}-\mathrm{C} / \mathrm{C}-\mathrm{OH}$ and $\mathrm{C}-\mathrm{F}$, respectively. After treatment at both $50 \mathrm{~W}$ and $100 \mathrm{~W}, \mathrm{C}-\mathrm{F}$ bonds are observed. Furthermore, an increase in the treatment power results in a larger C-F peak.

Table 2: Elemental composition of glass fibre surface before and after treatment.

\begin{tabular}{|c|c|c|c|c|c|c|c|c|c|}
\hline \multirow{2}{*}{ Power $[\mathrm{W}]$} & \multirow{2}{*}{ Bundle location } & \multicolumn{6}{|c|}{ Elemental composition [at.\%] } & \multirow{2}{*}{$\mathrm{O}: \mathrm{C}$} & \multirow{2}{*}{$\mathrm{F}: \mathrm{C}$} \\
\hline & & $\mathrm{C}$ & $\mathrm{O}$ & $\mathrm{F}$ & $\mathrm{N}$ & $\mathrm{Si}$ & $\mathrm{Ca}$ & & \\
\hline \multirow{2}{*}{ - } & Interior & 76.0 & 22.9 & 0.0 & 0.0 & 1.1 & 0.0 & 0.29 & 0 \\
\hline & Exterior & 76.8 & 21.9 & 0.0 & 0.0 & 1.3 & 0.0 & 0.29 & 0 \\
\hline \multirow{2}{*}{50} & Interior & 74.7 & 23.3 & 1.4 & 0.0 & 0.6 & 0.0 & 0.31 & 0.040 \\
\hline & Exterior & 75.1 & 23.4 & 1.5 & 0.0 & 0.0 & 0.0 & 0.36 & 0.043 \\
\hline \multirow{2}{*}{100} & Interior & 72.9 & 23.5 & 3.6 & 0.0 & 0.0 & 0.0 & 0.33 & 0.055 \\
\hline & Exterior & 71.1 & 23.1 & 5.3 & 0.4 & 0.0 & 0.1 & 0.32 & 0.056 \\
\hline
\end{tabular}

\section{Discussion}

Atmospheric pressure plasma treatment with $\mathrm{He} / \mathrm{CF}_{4}$ at different plasma powers resulted in a decrease in wettability, as observed by the decrease in wetting rate, $\alpha$, in table 1 . The mean wetting rate is reduced by a factor of 22.8 after plasma treatment at $100 \mathrm{~W}$ and a factor of 7.6 after plasma treatment at $50 \mathrm{~W}$. This can be attributed to the introduction of fluorine onto the fibre sizing, as observed in the XPS results in table 2 and fig. 6, creating a PTFE type de-wetting behaviour. Treatment at $50 \mathrm{~W}$ introduced 

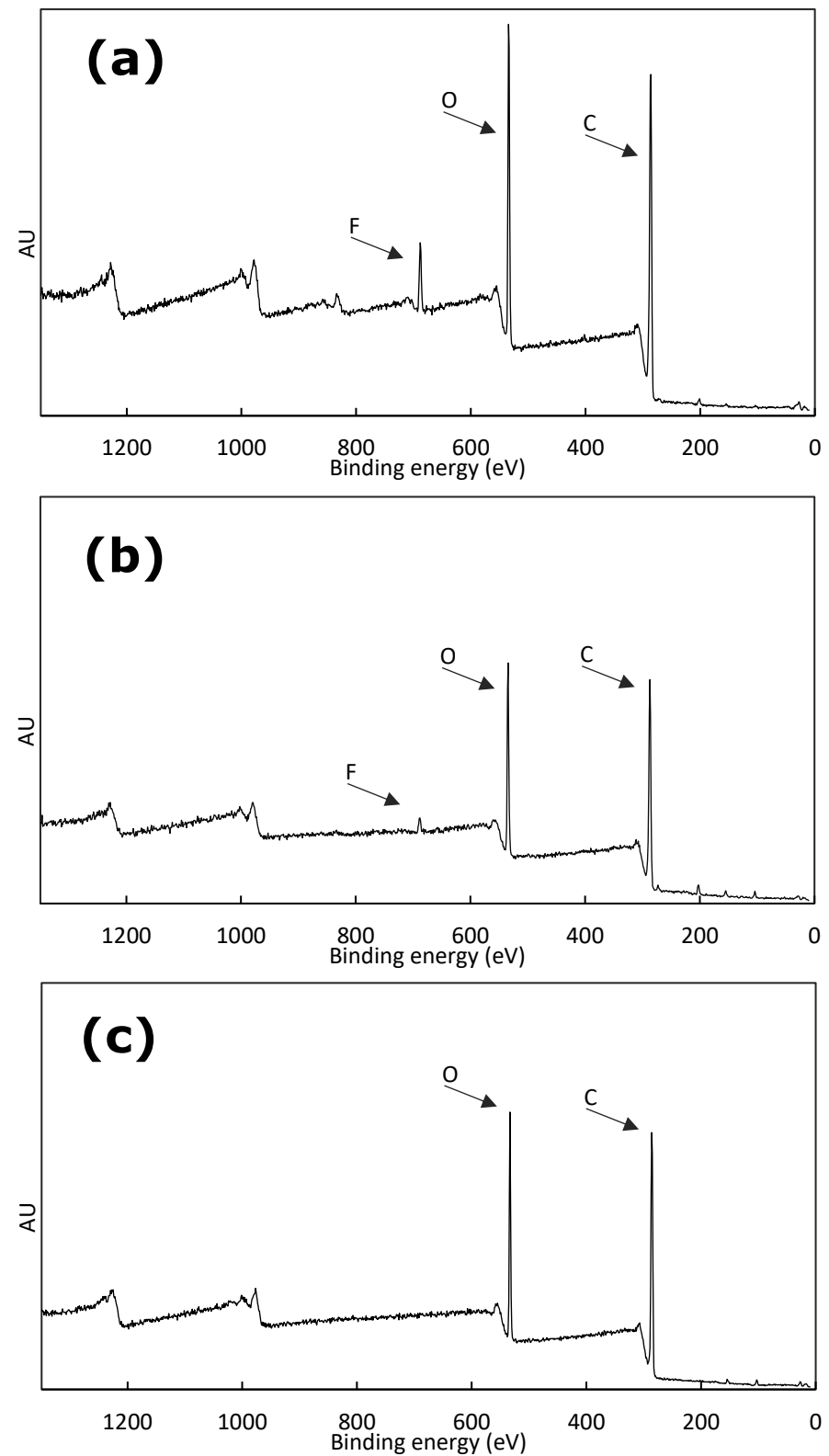

Figure 5: XPS spectra of treated and untreated fibres. (a) 100W DBD treatment, (b) 50 W DBD treatment, (c) untreated 

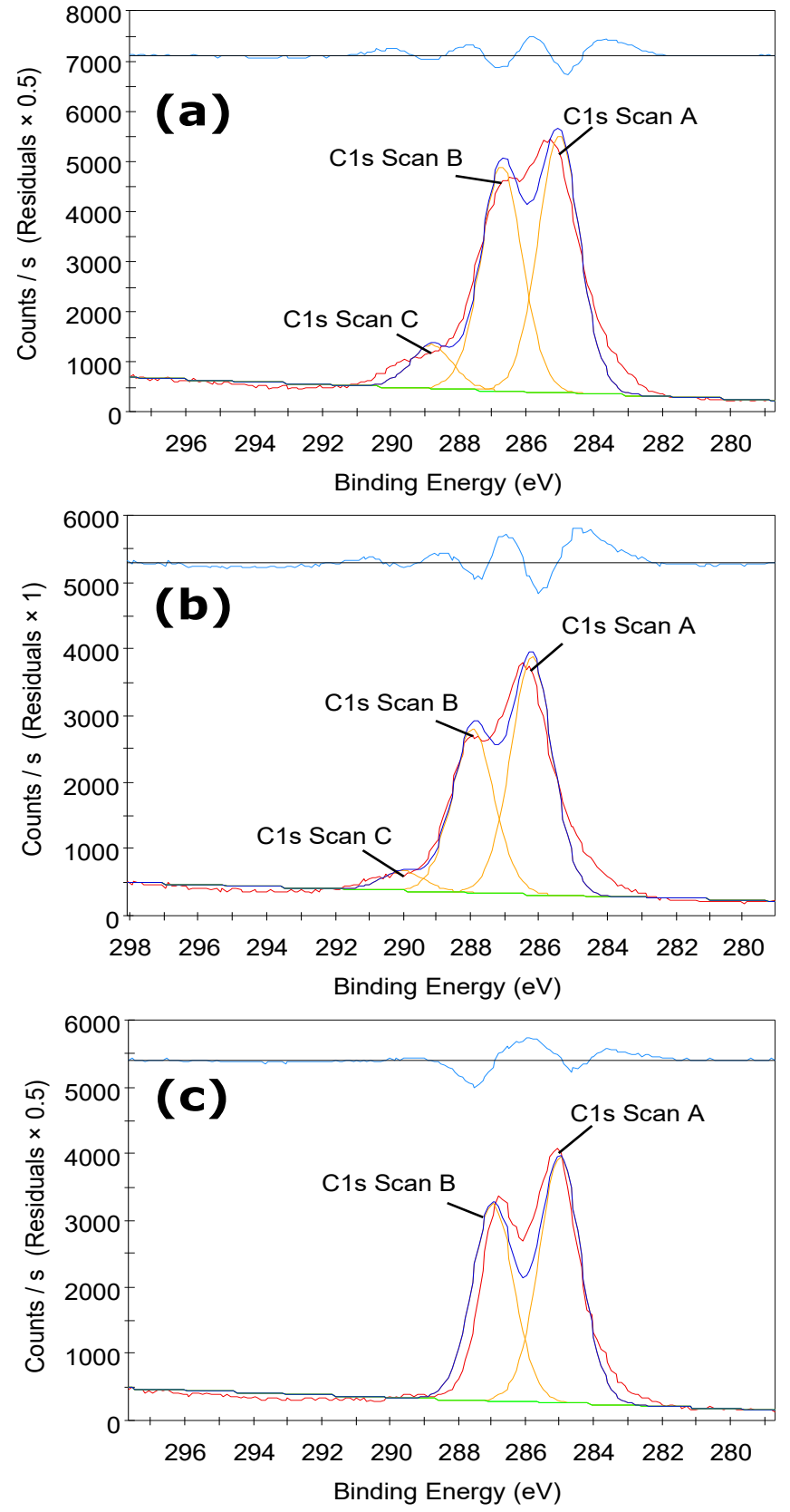

Figure 6: Typical C1s spectra of treated and untreated fibres. (a) 100W DBD treatment, (b) 50W DBD treatment, (c) untreated 
$1.4-1.5 a t . \%$ fluorine; at $100 \mathrm{~W}$ the fluorine content was $3.6-5.3 a t . \%$. Fluorine content was increased on fibres from the bundle interior as well as on fibres from the exterior, indicating that the plasma treatment was effective throughout the bundle cross-section. A comparable treatment method (DBD plasma in $\mathrm{O}_{2} / \mathrm{CF}_{4}$ on cellulose films) has been reported elsewhere ${ }^{[19]}$ with an introduction of 20.3 at.\% fluorine resulting in a water contact angle increase from $42.1^{\circ}$ to $92^{\circ}$, i.e. a significant de-wetting behaviour. This may be used in a composite structure to introduce a weak plane between plies, similar to a foil of PTFE.

Increased surface roughness on the micro and nano scales are able to increase the hydrophobicity of an already hydrophobic surface. ${ }^{[12]}$ Since a factor 1.8 difference in fluorine content was observed for the $50 \mathrm{~W}$ and $100 \mathrm{~W}$ treatments, leading to a factor 3 decrease in wetting rate, it is possible that the plasma treatment at a higher power also influenced the resulting topography. FE-SEM images showed signs of surface cracking in untreated and plasma treated specimens, however no clear difference in roughness could be observed between the treated and untreated fibres. Morphological change ${ }^{[16]}$ was not observed on the sizing surface. Further analysis by atomic force microscopy (AFM) is suggested for nano scale topographical characterization of the surface since this is not detectable by FE-SEM.

A minor increase of the O:C ratio after DBD treatment was observed for the plasma treated samples, indicating that the treatment had an oxidizing effect. This is attributed to $\mathrm{O}_{2}$ and moisture contamination from the ambi- 
ent air. ${ }^{[15,20]}$

The curve fit constant, A (table 1), does not show a significant difference for treated or untreated surfaces with the mean of constant, A, showing at most a $12 \%$ difference. The value of $\mathrm{A}$ is related to the contact angle at time $=0$ (evaluating eq. (1) at $t=0$ ). Therefore, a static contact angle measurement on a bundle of fibres is not sensitive enough to indicate the effect of surface modification. Repeatable results of the dynamic micro-wetting test however shows that $\alpha$, a temporal measurement, can give a better indication of surface modification than the constant A.

\section{Conclusion}

A DBD plasma in $\mathrm{He} / \mathrm{CF}_{4}$ can introduce fluorine onto sized glass fibre surfaces. Fluorine contents measured on fibres from the bundle interior and exterior indicate that the treatment was effective on fibres throughout the bundle. By introducing fluorine (1.4-5.3 at.\%), wetting rates with glycerol are significantly reduced (factor 7.6-22.8) for fibres treated with plasma in $\mathrm{He} / \mathrm{CF}_{4}$. The dynamic micro-wetting test can successfully show the change in wetting rates after treatment at different plasma power levels and is therefore a useful tool to characterize wetting of fibre bundles. 


\section{Acknowledgements}

The DACOMAT project has received funding from the European Union's Horizon 2020 research and innovation programme 5 under GA No. 761072. Special thanks to Gitte Christiansen for preparation of the microscopy specimens.

\section{References}

[1] Overgaard, L. C. T.; Lund, E. Structural collapse of a wind turbine blade. Part B: Progressive interlaminar failure models. Compos. Part A Appl. Sci. Manuf. 2010, 41, 271-283.

[2] Lee, H. G.; Kang, M. G.; Park, J. Fatigue failure of a composite wind turbine blade at its root end. Compos. Struct. 2015, 133, 878-885.

[3] Mouritz, A. Review of z-pinned composite laminates. Compos. Part A Appl. Sci. Manuf. 2007, 38, 2383-2397.

[4] Dadfar, M.; Ghadami, F. Effect of rubber modification on fracture toughness properties of glass reinforced hot cured epoxy composites. Mater. Des. 2013, 47, 16-20.

[5] Rask, M.; Sørensen, B. F. Determination of the J integral for laminated double cantilever beam specimens: The curvature approach. Eng. Fract. Mech. 2012, 96, 37-48.

[6] Goutianos, S.; Sørensen, B. F. Fracture resistance enhancement of layered structures by multiple cracks. Eng. Fract. Mech. 2016, 151, 92-108. 
[7] Kuhtz, M.; Hornig, A.; Richter, J.; Gude, M. Increasing the structural energy dissipation of laminated fibre composite materials by delamination control. Mater. Des. 2018, 156, 93-102.

[8] Yao, L.; Alderliesten, R. C.; Benedictus, R. The effect of fibre bridging on the Paris relation for mode I fatigue delamination growth in composites. Compos. Struct. 2016, 140, 125-135.

[9] Kusano, Y. Atmospheric pressure plasma processing for polymer adhesion: A review. J. Adhes. 2014, 90, 755-777.

[10] Li, R.; Ye, L.; Mai, Y.-W. Application of plasma technologies in fibrereinforced polymer composites: a review of recent developments. Compos. Part A Appl. Sci. Manuf. 1997, 28, 73-86.

[11] Kusano, Y.; Mortensen, H.; Stenum, B.; Goutianos, S.; Mitra, S.; Ghanbari-Siahkali, A.; Kingshott, P.; Sørensen, B.; Bindslev, H. Atmospheric pressure plasma treatment of glassy carbon for adhesion improvement. Int. J. Adhes. Adhes. 2007, 27, 402-408.

[12] Dimitrakellis, P.; Gogolides, E. Hydrophobic and superhydrophobic surfaces fabricated using atmospheric pressure cold plasma technology: A review. Adv. Colloid Interface Sci. 2018, 254, 1-21.

[13] Thomason, J. Glass fibre sizings: A review of the scientific literature; James L. Thomason, 2012.

[14] Xu, P.; Yu, Y.; Guo, Z.; Zhang, X.; Li, G.; Yang, X. Evaluation of composite interfacial properties based on carbon fiber surface chemistry and 
topography: Nanometer-scale wetting analysis using molecular dynamics simulation. Compos. Sci. Technol. 2019, 171, 252-260.

[15] Teodoru, S.; Kusano, Y.; Rozlosnik, N.; Michelsen, P. K. Continuous plasma treatment of ultra-high-molecular-weight polyethylene (UHMWPE) fibres for adhesion improvement. Plasma Process. Polym. 2009, 6, 375-381.

[16] Kusano, Y.; Madsen, B.; Berglund, L.; Oksman, K. Modification of cellulose nanofibre surfaces by $\mathrm{He} / \mathrm{NH} 3$ plasma at atmospheric pressure. Cellulose 2019, 26, 7185-7194.

[17] Shin, P.-S.; Baek, Y.-M.; Kim, J.-H.; Park, H.-S.; Kwon, D.-J.; Lee, J.H.; Kim, M.-Y.; DeVries, K. L.; Park, J.-M. Interfacial and wetting properties between glass fiber and epoxy resins with different pot lifes. Colloids Surfaces A Physicochem. Eng. Asp. 2018, 544, 68-77.

[18] Beamson, G.; Briggs, D. High resolution XPS of organic polymers, the Scienta ESCA300 database; Wiley: Chichester, 1992.

[19] Siró, I.; Kusano, Y.; Norrman, K.; Goutianos, S.; Plackett, D. Surface modification of nanofibrillated cellulose films by atmospheric pressure dielectric barrier discharge. J. Adhes. Sci. Technol. 2013, 27, 294-308.

[20] Kusano, Y.; Teodoru, S.; Hansen, C. M. The physical and chemical properties of plasma treated ultra-high-molecular-weight polyethylene fibers. Surf. Coatings Technol. 2011, 205, 2793-2798. 